\title{
Publisher's notice
}

This Tourism Economics Fast Track paper has been peer-reviewed, revised and fully accepted for publication in Tourism Economics. However, this is an unedited manuscript and will undergo a rigorous editing process before its appearance in an issue of the journal. This means that this manuscript version of the paper may not conform to journal style in terms of presentation, spelling and other usages. It may also contain minor errors of typography, grammar, spelling, referencing, etc, all of which will be corrected in the processes of copy-editing and proofreading.

Tourism Economics operates a Fast Track online publication system so that papers can be published and made available almost immediately on final acceptance by the journal.

\section{Citing this article}

Each Tourism Economics Fast Track article is given a DOI. When the paper is assigned to an issue, this DOI will automatically be transferred to the article in the journal issue.

This version of the article may be cited using the DOI. Citations should include the author's or authors' name(s), the title of the article, the title of the journal followed by the words 'Fast Track', the year of Fast Track publication and the DOI. For example:

Smith, J. (2016), ‘Article title’, Tourism Economics Fast Track, DOI xxxxxxxx.

Once the paper has been published in an issue of the journal, the DOI will automatically resolve to that final version and the article can be cited in accordance with normal bibliographical conventions.

Article copyright (C) 2016 IP Publishing Ltd.

doi: 10.5367/te.2015.0537 
RESEARCH NOTE

SPORTS RESULTS CREATING TOURISM VALUE:

Rafael Nadal's tennis match points worth $€ 12,000,000$

\author{
Juan Luis Nicolau \\ Dept. of Marketing \\ Faculty of Economics \\ University of Alicante \\ PO Box 99 \\ 03080 Alicante \\ SPAIN \\ Corresponding author’s e-mail: jl.nicolau@ua.es \\ María Jesús Santa-María \\ Dept. of Applied Economics and Economic Policy \\ Faculty of Economics \\ University of Alicante \\ PO Box 99 \\ 03080 Alicante \\ SPAIN
}




\title{
SPORTS RESULTS CREATING TOURISM VALUE: Rafael Nadal's tennis match points worth $€ 12,000,000$
}

\begin{abstract}
The purpose of this article is to examine the effect of a tennis player's performance in the Grand Slams on the market value of a leading airline from the player's country. The analysis is applied to the Spanish airline, Iberia, and the Spanish tennis player, Rafael Nadal. It shows that his victories in the matches of the Grand Slam tennis tournaments led to an increase in the market value of Iberia. The result is confirmed by both the victory itself and the difference between sets in favour and sets against in the match.
\end{abstract}

Keywords: image; firm value; loss aversion; tennis; sports tourism; airlines

\section{INTRODUCTION}

Sports tourism, in which people "participate in a sports activity, recreationally or competitively, travel to observe sport at grassroots or elite level, and travel to visit a sports attraction” (Barquet et al., 2011; Delpy-Neirotti, 2003; Falk, 2015) has been widely analyzed, especially its impact on the destination (Dwyer et al., 2006; Huang et al., 2014; Liu and Gratton, 2010). In other research areas, the study of sports celebrities has focused on the endorsement contracts and their effects on the endorsing firms (Ding et al., 2011).

The combination of these two research lines leads to a topic that has been overlooked in the tourism literature: the sports celebrities' implicit promotion of their countries -as tourism destinations- via secondary associations. According to Keller (1993), secondary associations are links of the brand to other information in the 
memory that does not have a direct relationship with the brand, but that consumers might identify with it and thus assume that both entities share associations. This author suggests that these secondary associations can be related to the company, the distribution channels, the country of origin and celebrity endorsers.

In this line, we can regard athletes as celebrity endorsers, thereby creating secondary associations -explicitly with the firms they are endorsing and implicitly with their country of origin-. Note that firms contract celebrity endorsers because they make advertisements more reliable, help people recognize and remember the brand name, generate affect towards the brand, and increase the likelihood of individuals choosing the endorsed brand (Agrawal and Kamakura, 1995). Analogously, and irrespective of these contracts with private firms, the athlete's country's name also gets the advantages of sponsorship activities and celebrity endorsers without the large expenses that these strategies usually imply. Note that the country's name is linked to the athlete not because of a costly sponsorship relationship but because it is an essential part of the identity of the person.

Having athletes winning major hyped sports events can have a positive impact on the knowledge of the destination brand (that is, the athletes' country). Along this line, Nicolau (2012) shows that the victory of the Spanish National soccer team in the 2010 FIFA World Cup led to a significant increase in the tourism industry's market value, because of the positive effect of brand knowledge on firm value, via brand awareness and image (Joshi and Hanssens, 2010).

While this is the only study detected in the literature that has examined the impact of sports results on tourism, we focus on an individual athlete rather than a team. We argue that, on the one hand, having an athlete winning major sports contests can notably help the athlete's country build a positive image -via secondary associations-. It 
helps identify and differentiate the destination brand (Mackay and Fesenmaier, 2000), which in turn, can influence consumer evaluations of the brand and, consequently, brand choice (Woodside and Lysonski, 1989). On the other hand, the awareness of the country's brand after the athlete's victories is enhanced. The brand will be evoked under many different situations or circumstances much more easily and more frequently after the athlete's victories, increasing “consumers' ability to confirm prior exposure to the brand when given the brand as a cue”, i.e. brand recognition (Keller, 1993) and reinforcing “consumers' ability to retrieve the brand when given the product category”, i.e. brand recall (Keller, 1993). Thus, when considering a list of possible countries to go on holidays, the winning country will be recognized on that list, and more importantly, it is more likely to be recalled when forming the list.

To sum up, the underlying idea is that the positive impact of celebrated athletes' victories on their countries -whose names are tourism destination brands- can lead to an increase in the likelihood of the destination being included in a potential tourist's consideration set. This increase stems from enhancing the country's brand knowledge via brand awareness (brand recognition and brand recall) and secondary associations (brand image). Consequently, raising the likelihood of the destination being included in a tourist's consideration set leads to augmenting the probability of the country being chosen as a destination. Eventually, this increase in potential tourists should result in an increment in sales and profits on the part of tourism firms, with a subsequent positive effect on firm value.

Accordingly, in this research note, we test whether the performance of a tennis player in the four major tennis tournaments (the Grand Slams) has an effect on a critical tourism sub-sector, which is the airline industry. Note that the paper does not explicitly deals with passenger flows but with stock market's reactions; reactions which are made 
by shareholders. Certainly, the brand enhancement is expected to have a greater effect on inbound tourism but we can only know the exact impact of this effect a posteriori. In this regard, the advantage of the method used in the paper is that we can anticipate the profits of an airline by looking at investors' reactions.

\section{METHOD AND DATA}

To examine the effect of a tennis player's performance on the value of an airline we estimate the abnormal returns derived from the player's performance in each match. We use the traditional market model to gauge the variation in share prices on any given day:

$$
R_{i t}=\alpha_{i}+\beta_{i} R M_{t}+\varepsilon_{i t}
$$

where $R_{i t}$ represents the returns on the firm's share $i$ on day $t ; R M_{t}$ is the rate of returns on the market portfolio on day $t$; the parameters $\alpha_{i}$ and $\beta_{i}$ represent the constant and the systematic risk on share $i$, respectively; and $\varepsilon_{i t}$ is the error term (in order to control for kurtosis and heteroskedasticity in the error term, we estimate an EGARCH $(1,1)$ model)

To calculate the abnormal returns derived from the results in each match, Karafiath's (1988) methodology is used. We add a dummy variable $D_{\text {iwt }}$ to the expression (1), which indicates the day after winning a match. The resulting market model is as follows:

$$
R_{i t}=\alpha_{i}+\beta_{i} R M_{t}+\xi_{i} D_{i w t}+\varepsilon_{i t}
$$

where $\xi_{i}$ is a parameter to be estimated and expected to be positive if the victory has a positive effect. Also interesting is the analysis of potential differential effects of the abnormal returns derived from each match result, i.e. whether the variation in the market value differs in magnitude when the sports result is positive (won match) or 
negative (lost match). Thus, we build a second model with a dummy variable $D_{i t}$, which indicates the first trading day after the match on day $t$ and two result variables: $W I N_{t}$ and LOSS $_{t}$. Calling $S F_{t}$ sets in favor and $S A_{t}$ sets against, these two variables WIN $_{t}$ and $L_{O S S}$ are defined as follows:

$W I N_{t}=\left(S F_{t}-S A_{t}\right) D_{W}$, where $D_{W}=1$ if $S F_{t}-S A_{t}>0$ and $D_{W}=0$ otherwise.

$\operatorname{LOSS}_{t}=\left(S F_{t}-S A_{t}\right) D_{L}$, where $D_{L}=1$ if $S F_{t}-S A_{t}<0$ and $D_{L}=0$ otherwise.

The final market model is:

$$
R_{i t}=\alpha_{i}+\beta_{i} R_{m t}+\theta_{i} W_{1} D_{t} D_{i t}+\tau_{i} \text { LOSS }_{t} D_{i t}+\varepsilon_{i t}
$$

In line with Kahneman and Tversky’s (1979) Prospect Theory, loss aversion will exist if $\tau_{i} / \theta_{i}>1$, i.e. if the parameter associated with the set difference in a defeat is greater than the parameter related to the set difference in a victory.

We apply the empirical analysis to Iberia, which is the leading airline in Spain, whose raw data are the daily returns on the firm during the period April 3, 2001 to January 1, 2011; and the tennis player chosen is Rafael Nadal, who is currently the best Spanish tennis player. We focus on the Grand Slam tennis tournaments (Australian Open, Roland Garros, Wimbledon and US Open), and the results for the 85 matches used are obtained from the Worldwide Tennis Database.

\section{RESULTS}

Equation 1 in Table 1 presents the parameter estimates for the effect of winning a tennis match in the Grand Slams. We find a significantly positive parameter for the variable $D_{i w t}$, which represents abnormal returns for the day after Nadal winning a match; thus, Nadal's victory seems to have a positive effect on Iberia's market value via destination brand knowledge enhancement, in line with Joshi and Hanssens (2010). 
"Insert Table 1 about here"

Equation 2 in Table 1 shows the effects of winning or losing a match in the Grand Slams. We find a positive and significant parameter for the variable "won match 3 set difference" and a non-significant parameter for "lost match 3 set difference”, meaning that Nadal's performance in the court has different effects on the firm's market value: winning enhances firm value, but contrary to loss aversion, if he loses a match the market value of Iberia is not affected. As Nadal's losing a match is something that happens not frequently and only every now and again, even being it an unanticipated event, the market seems to remain neutral.

Finally, to show the implication of this result in economic terms, we estimate the economic impact of winning. For an average sample market value of about $€ 2$ billion (the result of multiplying the number of shares by their share price), positive abnormal returns of $0.58 \%$ derived from a won match (with a set difference of one) means an increase in market value of around $€ 12$ million in one single day.

\section{CONCLUSIONS}

This research note analyzes the relationship between the performance of a celebrated tennis player in the Grand Slams and the market value of the leading airline in the player's country. We find that Nadal's victories in the matches of the Grand Slams lead to an increase in the market value of Iberia, via brand knowledge enhancement of the player's country's name. This result is confirmed by both, the victory itself and the difference between sets in favor and sets against.

This outcome opens up further avenues of research. First, the fact that Nadal's performance only has an effect on firm value when the sports result is positive proves him as an asset: having him as an endorser guarantees no losses in firm value. It means 
that the endorser's characteristics are worthwhile analyzing. Second, other sports can produce (dis)similar results, so a multi-sports study could detect idiosyncrasies that might make their effects on tourism firms vary. Third, the measurement of information exchange on the social media platforms (e.g Twitter) of the destination or a specific tourism company after the athlete's performance could give an idea of how much “hype” has been generated. 


\section{REFERENCES}

Agrawal, J. and Kamakura, W.A. (1995), “The economic worth of celebrity endorsers: an event study analysis”, Journal of Marketing, 59, 56-62.

Barquet, A.; Gabriel Brida, J.; Osti, L.; Schubert, S. (2011), “An analysis of tourists' expenditure on winter sports events through the Tobit censorate model”, Tourism Economics, 17, 6, pp. 1197-1217.

Delpy-Neirotti, L. (2003), An Introduction to Sport and Adventure Tourism. In S. Hudson (Ed.), Sport and Adventure Tourism (pp. 1-26). New York: The Haworth Hospitality Press.

Ding, H., Molchanov, A.E. \& Stork, P.A. (2011), “The value of celebrity endorsements: A stock market perspective”, Marketing Letters, 22,147-163.

Dwyer, L.; Forsyth, P. \& Spurr, R. (2006), “Assessing the Economic Impacts of Events: A Computable General Equilibrium Approach”, Journal of Travel Research, 45(1), 59-66.

Falk, M. (2015), “The demand for winter sports: empirical evidence for the largest French ski-lift operator”, Tourism Economics, 21, 3, pp. 561-580.

Huang, H.; Mao, L.uke L.; Kim, S.K.; Zhang, J.J. (2014) “Assessing the economic impact of three major sport events in China: the perspective of attendees”, Tourism Economics, 20, 6, pp. 1277-1296.

Joshi, A. and Hassens, M. (2010), “The direct and indirect effects of advertising spending on firm value”, Journal of Marketing, 74, 20-33.

Kahneman, D. and Tversky, A. (1979), "Prospect theory: and analysis of decision under risk”, Econometrica, 47(2), 263-291.

Karafiath, I. (1988), "Using Dummy Variables in the Event Methodology”, The Financial Review, 23(3), 351-357. 
Keller, K.L. (1993), “Conceptualizaing, measuring, and managing customer-based brand equity”, Journal of Marketing, 57, 1-22.

Liu, D.; Gratton, C. (2010), “The impact of mega sporting events on live spectators' images of a host city: a case study of the Shanghai F1 Grand Prix”, Tourism Economics, 16, 3, pp. 629-645.

MacKay, K.J. and Fesenmaier, D.R. (2000), “An Exploration of Cross-Cultural Destination Image Assessment”, Journal of Travel Research, 38, 4, 417-423.

Nicolau, J.L. (2012), “The effect of winning the 2010 FIFA World Cup on the tourism market value: The Spanish case”, Omega, 40(5), 503-510.

Woodside, A.G. and Lysonski, S. (1989), “A General Model Of Traveler Destination Choice”,. Journal of Travel Research, 27, 4, 8-14. 
Table 1. Effect of Grand Slam matches on airline value

\begin{tabular}{|c|c|c|c|c|}
\hline Variables & \multicolumn{2}{|c|}{ Equation 1} & \multicolumn{2}{|c|}{ Equation 2} \\
\hline & Parameters & z-statistic & Parameters & z-statistic \\
\hline Market portfolio & 0.7157 & 30.03 & 0.7154 & 30.36 \\
\hline$\left(\boldsymbol{R}_{m}\right)$ & $(0.0238)$ & & (0.0235) & \\
\hline Victory & 0.0058 & 2.29 & & \\
\hline$\left(D_{i w t}\right)$ & $(0.0025)$ & & & \\
\hline \multirow{2}{*}{$\begin{array}{l}\text { Set difference } x \text { Won match } \\
(W I N)\end{array}$} & & & 0.0058 & 2.30 \\
\hline & & & $(0.0025)$ & \\
\hline \multirow{2}{*}{$\begin{array}{l}\text { Set difference } x \text { Lost match } \\
\text { (LOSS) }\end{array}$} & & & 0.0034 & 0.26 \\
\hline & & & (0.0129) & \\
\hline \multirow[t]{2}{*}{$\alpha$} & -0.00007 & -0.21 & -0.0001 & -0.29 \\
\hline & $(0.0003)$ & & $(0.0003)$ & \\
\hline \multirow[t]{2}{*}{$\mathbf{c}$} & -0.3246 & -11.32 & -0.3927 & -11.53 \\
\hline & $(0.0286)$ & & $(0.0340)$ & \\
\hline \multirow[t]{2}{*}{$\lambda_{\operatorname{Arch}(1)}$} & 0.1813 & 15.72 & 0.1971 & 15.19 \\
\hline & $(0.0115)$ & & (0.0129) & \\
\hline \multirow[t]{2}{*}{$\delta$ Garch(1) } & -0.0377 & -4.810 & -0.0392 & -4.67 \\
\hline & $(0.0078)$ & & $(0.0084)$ & \\
\hline \multirow{2}{*}{$\gamma_{\text {Egarch(1) }}$} & 0.9751 & 330.02 & 0.9678 & 275.14 \\
\hline & $(0.0029)$ & & $(0.0035)$ & \\
\hline F-statistic & \multicolumn{2}{|c|}{63.76} & \multicolumn{2}{|c|}{54.63} \\
\hline R-squared & \multicolumn{2}{|c|}{0.1344} & \multicolumn{2}{|c|}{0.1344} \\
\hline
\end{tabular}

